\title{
Effect of intravitreal aflibercept on corneal endothelial cells: a 6-month follow-up study
}

This article was published in the following Dove Medical Press journal: Clinical Ophthalmology

\section{Tetsuya Muto \\ Shigeki Machida}

Department of Ophthalmology, Dokkyo Medical University Saitama Medical Center, Koshigaya, Japan
Correspondence: Tetsuya Muto Department of Ophthalmology, Dokkyo Medical University Saitama Medical Center, 2-I-50 Minamikoshiagya, Koshigaya 343-8555, Japan

$\mathrm{Tel}+8 \mid 48965$ IIII

Fax $+8 \mid 48965$ II 27

Email ueda.castle@gmail.com
Purpose: To determine the effect of intravitreal aflibercept injection on the corneal endothelium in patients with diabetic or cystoid macular edema caused by retinal vein occlusion.

Material and methods: Forty-six eyes of 44 consecutive patients ( 27 men, 17 women; age range: 55-88 years) were evaluated. All participants initially received a single intravitreal injection of aflibercept ( $2 \mathrm{mg}$ in $0.05 \mathrm{~mL}$ ), followed by pro re nata use and underwent central corneal specular microscopy before the injection and at 1,3 and 6 months after the first injection during a 6-month follow-up period. The endothelial cell density (ECD), average cell size (AVG), standard deviation of cell size (SD), coefficient of variation of cell size $(\mathrm{CoV})$, maximum of cell size (MAX), minimum of cell size (MIN) and percentage of hexagonal cells (Hex\%) were analyzed and the central corneal thickness (CCT) was measured.

Results: No significant differences in the ECD, AVG, SD, CoV, MIN, Hex\% and CCT were observed between measurements obtained before and 1, 3 and 6 months after the first injection. However, the MAX measured before injection differed significantly from the values measured at 1,3 and 6 months after the first injection $(P=0.033)$. An average of $1.43 \pm 0.58$ intravitreal aflibercept injections were administered per patient.

Conclusion: These study findings indicate that the intravitreal administration of aflibercept ( $2 \mathrm{mg}$ ) might very slightly alter the corneal endothelium within 6 months of the first injection. Keywords: corneal endothelium, macular edema, retinal vein occlusion, vascular endothelial growth factor

\section{Introduction}

The recombinant fusion protein aflibercept (Eylea ${ }^{\circledR}$; Regeneron, Tarrytown, NY, USA) is composed of vascular endothelial growth factor (VEGF)-binding receptors-1 and -2 fused to the Fc portion of human immunoglobulin G. ${ }^{1}$ This agent was first approved in the United States for the treatment of neovascular age-related macular degeneration. ${ }^{2}$ Notably, an increased VEGF level as measured in vitreous samples has been identified as the main cause of both diabetic macular edema (DME) and cystoid macular edema (CME) due to retinal vein occlusion (RVO). Aflibercept has been proven effective for CME due to central retinal vein occlusion (CRVO) in COPERNICUS and GALILEO studies ${ }^{2-4}$ and for DME in VIVID, VISTA ${ }^{5}$ and DA-VINC ${ }^{6}$ studies. It has also been proven effective for CME due to branch retinal vein occlusion (BRVO) in the VIBRANT study. ${ }^{7}$ Given these promising characteristics, Japan approved the use of aflibercept for the treatment of DME in November 2014, for CME due to CRVO in November 2013 and for CME due to BRVO in June 2015. This drug has since become the standard of care for treatment of these diseases in Japan.

In humans, the pharmacokinetic profile of aflibercept after intravitreal injection has not yet been determined definitively. However, a study found that bevacizumab, 
another recombinant humanized VEGF-binding monoclonal antibody, can be detected in the anterior chamber of the eye at 1 month after intravitreal injection. ${ }^{8}$ However, as VEGF and its receptors are expressed in the corneal endothelium, ${ }^{9-11}$ which facilitated the progression of severe corneal changes in humans treated with bevacizumab. ${ }^{12}$ Therefore, aflibercept may also affect VEGF function in the corneal endothelium following intravitreal injections into the vitreous humor. Aflibercept was also shown to interfere with the physiology of retinal pigment epithelial cells ${ }^{13}$ and to negatively affect the proliferation and viability of mesenchymal stem cells derived from the ciliary body and limbus in a concentrationdependent manner. ${ }^{14}$

Aflibercept has a predicted longer intravitreal activity than ranibizumab, ${ }^{15}$ which suggests a stronger potential for both beneficial and adverse effects. The above findings suggest that it is reasonable to consider whether this drug is potentially cytotoxic to human corneal endothelial cells. Lass et $\mathrm{al}^{16}$ reported that intravitreal injections of aflibercept did not affect the corneal endothelium in patients with unilateral neovascular age-related macular degeneration. The corneal endothelial cells are known to be susceptible to surgical insults in diabetes. The number of corneal endothelial cells is prone to reduce in diabetic eyes compared to that in nondiabetic eyes after cataract surgery. ${ }^{17,18}$ Therefore, the intravitreal injection of aflibercept may place significant stress on the corneal endothelial cells of diabetic patients.

As specular microscopy with morphometric analysis is a sensitive indicator of endothelial cell function, ${ }^{19,20}$ we used this technology to prospectively analyze in vivo corneal endothelial toxicity after intravitreal injection of aflibercept for the treatment of DME and CME due to RVO.

\section{Material and methods}

Forty-six eyes of 44 consecutive patients with DME and CME due to RVO were recruited for this observational prospective case series study. The study protocol was approved by the Institutional Review Board of the Dokkyo Medical University Saitama Medical Center, and the study was conducted in accordance with the tenets of the Declaration of Helsinki. All participants provided written informed consent.

The inclusion criteria were clinical signs and angiographic evidence of DME and CME due to RVO with a best-corrected visual acuity (VA) of 20/30 or worse; an age of $\geq 50$ years; no history of contact lens use; no ocular disease that could alter the corneal endothelium morphology, such as Fuchs' corneal dystrophy or iridocorneal endothelial syndrome; no intraocular surgery within a 6-month period before and after aflibercept injection; no laser treatment within a 2-month period before and 6-month period after the injection; no anti-VEGF antibody injection within a 6-month period before the injection and an endothelial cell count of $>1,500 / \mathrm{mm}^{2}$ before the initial aflibercept injection.

All patients initially received a single intravitreal injection of aflibercept ( $2 \mathrm{mg}$ in a total volume of $0.05 \mathrm{~mL}$ ), followed by pro re nata use according to the study protocol. All patients were followed for 6 months and underwent VA testing, slit-lamp examination, IOP measurement using Goldmann applanation tonometry and indirect ophthalmoscopy, and optical coherence tomography (PLEX Elite 9000; Carl Zeiss Meditec, Inc, Dublin, CA, USA) examinations were performed at baseline and before the administration of aflibercept. The treatment effect was monitored based on improvements in VA and optical coherence tomography measurements.

\section{Intravitreal aflibercept injection technique}

Conjunctival anesthesia was topically induced by instillation of 4\% lidocaine (Xylocaine ${ }^{\circledR}$ solution 4\%; Aspen Japan, Tokyo, Japan). The eyelids and ocular surface were disinfected with $0.027 \%$ iodine (PA.IODO ${ }^{\circledR}$ Ophthalmic and Eye washing Solution; Nitten Pharmaceutical Co, Ltd, Nagoya, Japan). In an operating room, aflibercept was injected into the superotemporal quadrant via the pars plana and into the vitreous cavity 3-4 $\mathrm{mm}$ posterior to the limbus using a 32-gauge needle. The post-injection light perception was assessed. A topical $0.5 \%$ levofloxacin solution $\left(0.5 \% \mathrm{Cravit}^{\circledR}\right.$ ophthalmic solution; Santen Pharmaceutical, Osaka, Japan) was instilled four times daily for 3 days before and after each intravitreal injection.

\section{Endothelial cell analysis}

Noncontact specular microscopy of the central cornea was performed using a specular microscope (CEM-530; NIDEK, Tokyo, Japan) that could measure corneal endothelial cell density $(E C D)$ in a small area $(0.25 \times 0.55 \mathrm{~mm})$. Corneal endothelial images before and 1, 3 and 6 months after the initial intravitreal aflibercept injection were obtained by experienced ophthalmic technicians. The specular microscope automatically evaluated the ECD, average cell size (AVG), standard deviation of cell size (SD), coefficient of variation of cell size (CoV), maximum of cell size (MAX), minimum of cell size (MIN) and percentage of the hexagonal cells (Hex\%). The specular microscopy also provided measurements of optical pachymetry and evaluated the central corneal thickness. 


\section{IOP measurement}

The first author (TM) measured the IOP before and 1, 3 and 6 months after the initial intravitreal injection of aflibercept. The IOP was measured once at each time point.

\section{Statistical analysis}

All data are expressed as mean \pm SD. Differences between preinjection and postinjection measurements were evaluated using a one-way ANOVA with the Dunnet's multiple comparison posttest. Differences between the treated and untreated eyes were evaluated using an unpaired $t$-test. Differences between patients with DME and CME due to RVO were evaluated using an unpaired $t$-test. Differences between single and multiple injections were evaluated using an unpaired $t$-test. The statistical analysis was performed using StatMate version V for Macintosh (ATMS, Tokyo, Japan). A $P$-value $<0.05$ was considered to indicate significance.

\section{Results}

The study group included 27 men and 17 women with a mean age of 72.1 years (range, 55-88 years). Of the treated eyes, $27(58.7 \%)$ and 19 (41.3\%) were phakic and pseudophakic, respectively; the corresponding values were $22(47.8 \%)$ and $24(52.2 \%)$ for the untreated eyes. None of the pseudophakic eyes had a damaged posterior capsule. Eighteen, seven and 19 patients had DME, CME due to CRVO and CME due to BRVO, respectively. Patients with DME and CME due to RVO had mean ages of 67.5 (range, 60-82 years) and 75.3 years (range, 55-88 years), respectively. Five of 26 patients with CME due to RVO had diabetes. Ten eyes in patients with CME due to RVO received two intravitreal injections of aflibercept while 16 eyes received single intravitreal injections. Among patients with DME, six eyes received two intravitreal injections, two eyes received three injections and eleven eyes received a single injection. Overall, the per-patient average number of injections was $1.43 \pm 0.58$, with an average of $1.53 \pm 0.70$ and $1.39 \pm 0.50$ injections in patients with DME and CME due to RVO, respectively. Among eyes that received multiple $(>1)$ injections, an average of $2.11 \pm 0.32$ injections were administered. All patients completed the 6-month follow-up. No systemic or ocular adverse events were recorded during this period.

\section{ECD and morphology}

The following normal score ranges were set for each parameter: ECD: $2,777-3,410$ cells $/ \mathrm{mm}^{2}$; AVG: $296-367 \mu \mathrm{m}^{2}$; CoV: 0.26-0.40; Hex: 55\%-67\%. ${ }^{21}$ The measurements obtained before and at 1, 3 and 6 months after the first intravitreal aflibercept injection from patients with DME and CME due to RVO are presented in Table 1. Of all evaluated parameters, only MAX differed significantly from before to after the intravitreal injections at any time point. The photographs of the endothelial cells and optical coherence tomography of a representative eye are presented in Figure 1A-D.

The measurements obtained at all time points were compared between the treated and untreated eyes, and the results are presented in Tables 2 and 3. Again, of all evaluated parameters, only MAX differed significantly at 6 months after the intravitreal injections.

The measurements obtained at all time points were also compared between patients with DME and those with CME due to RVO, and the results are presented in Tables 4 and 5 . No significant differences were observed in any of the evaluated parameters from before to after the intravitreal injections at any time point.

Table I Morphometric analysis of the corneal endothelium in the treated eye before and after intravitreal injections of aflibercept in patients with DME and CME due to RVO

\begin{tabular}{l|l|l|l|l|l}
\hline & Before injection & I month Al & 3 months Al & 6 months Al & P-value \\
\hline ECD $\left(\mathrm{cells} / \mathrm{mm}^{2}\right)$ & $2,515.0 \pm 422.3$ & $2,528.5 \pm 44 I .5$ & $2,500.0 \pm 427.1$ & $2,550.5 \pm 45 I . I$ & 0.95 \\
AVG $\left(\mu \mathrm{m}^{2}\right)$ & $410.7 \pm 81.4$ & $412.5 \pm 96.7$ & $415.5 \pm 98.0$ & $409.0 \pm 103.8$ & 0.99 \\
SD $\left(\mu \mathrm{m}^{2}\right)$ & $111.2 \pm 32.4$ & $111.8 \pm 32.9$ & $115.2 \pm 33.8$ & $113.1 \pm 32.8$ & 0.94 \\
CoV & $28.4 \pm 4.5$ & $28.7 \pm 4.4$ & $29.4 \pm 5.6$ & $29.3 \pm 4.4$ & 0.70 \\
$\operatorname{MAX}\left(\mu \mathrm{m}^{2}\right)$ & $1,070.1 \pm 220.4$ & $1,138.9 \pm 25 I .5$ & $1,180.6 \pm 283.5$ & $1,041.5 \pm 238.7$ & 0.033 \\
$\operatorname{MIN}\left(\mu \mathrm{m}^{2}\right)$ & $146.3 \pm 28.4$ & $146.1 \pm 27.2$ & $145.0 \pm 16.2$ & $146.6 \pm 19.7$ & 0.99 \\
Hex $(\%)$ & $67.5 \pm 4.9$ & $67.6 \pm 5.3$ & $66.9 \pm 6.4$ & $66.5 \pm 6.0$ & 0.78 \\
CCT $(\mu \mathrm{m})$ & $541.7 \pm 27.8$ & $543.2 \pm 27.1$ & $541.7 \pm 29.1$ & $542.4 \pm 28.1$ & 0.99 \\
IOP $(\mathrm{mmHg})$ & $13.3 \pm 3.2$ & $12.5 \pm 2.7$ & $13.0 \pm 3.2$ & $12.8 \pm 2.9$ & 0.55 \\
\hline
\end{tabular}

Note: Data are presented as mean \pm SD

Abbreviations: Al, after injection; AVG, average cell size; CCT, central corneal thickness; CME, cystoid macular edema; CoV, coefficient of variation of cell size; DME, diabetic macular edema; ECD, endothelial cell density; Hex, hexagonal cells; MAX, maximum of cell size; MIN, minimum of cell size; RVO, retinal vein occlusion. 
A a

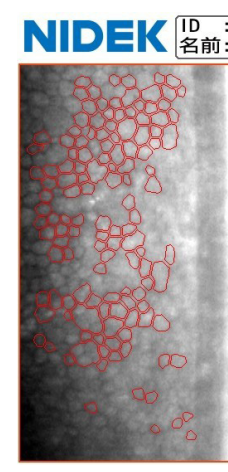

6840663

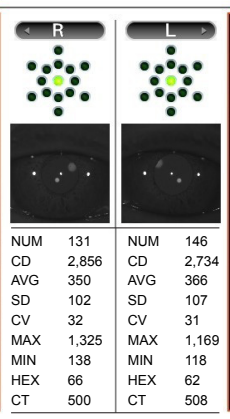

2017/03/29 12:02:35

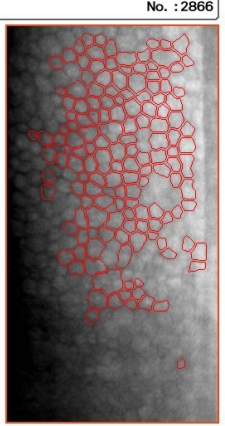

B a

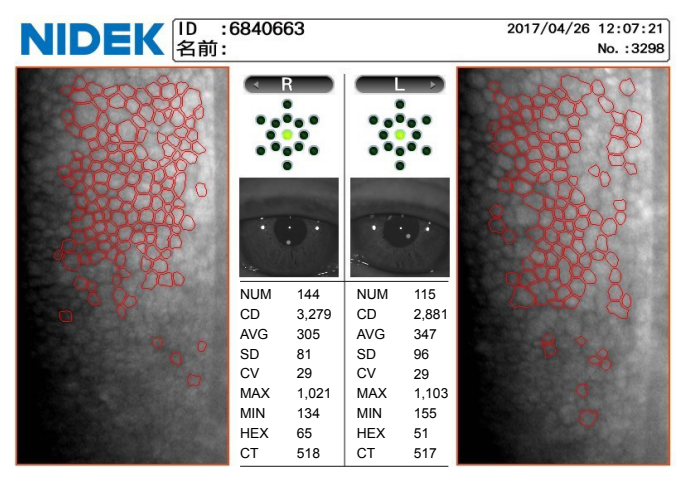

b

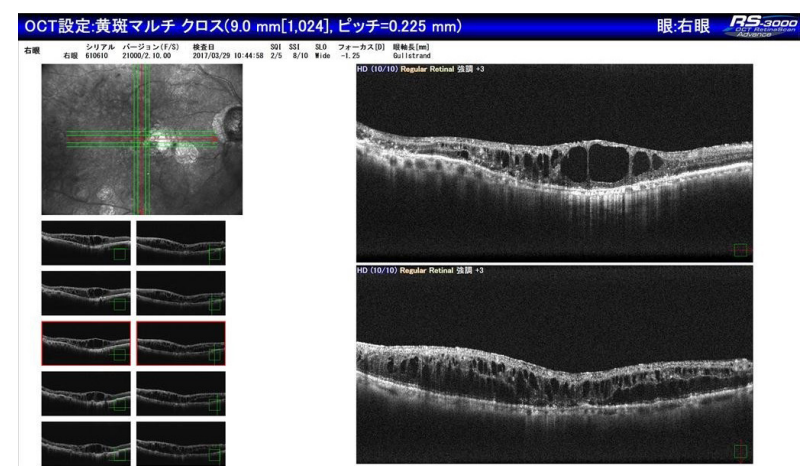

b

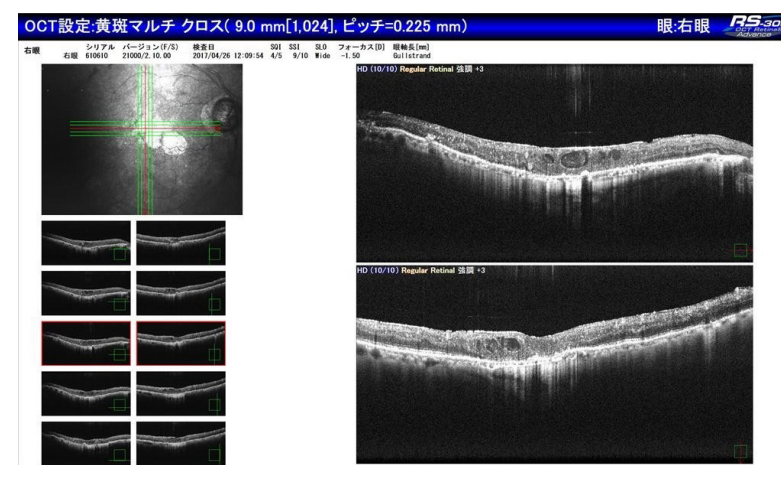

b

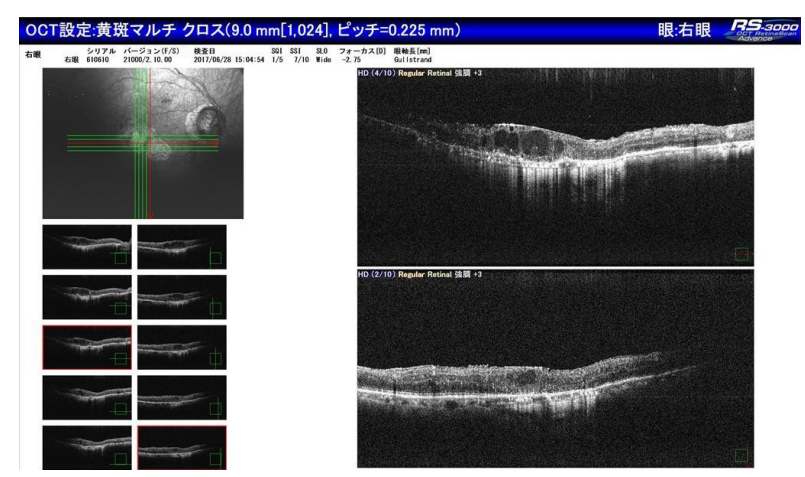

。

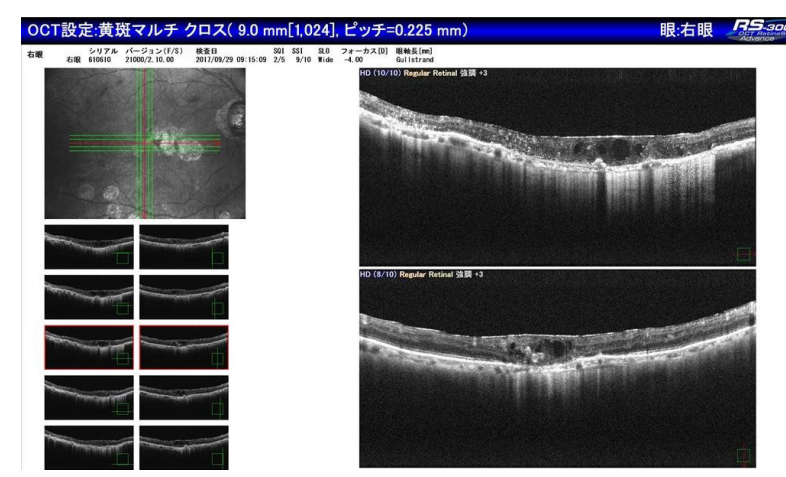

Figure I Specular microscopy of corneal endothelial cells and optical coherence tomography of a representative right eye in a patient with CME due to RVO. Notes: (A) Before injection and (B) I month, (C) 3 months and (D) 6 months after injection. (a) Specular microscopy and (b) optical coherence tomography. Abbreviations: CME, cystoid macular edema; RVO, retinal vein occlusion. 
Table 2 Morphometric analysis of the corneal endothelium in the treated and untreated eyes before and I month after the intravitreal injection of aflibercept in patients with DME and CME due to RVO

\begin{tabular}{l|l|l|l|l|l|l}
\hline & \multicolumn{2}{l}{ Before injection } & \multicolumn{2}{l}{ I month AI } \\
\cline { 2 - 7 } & Treated eyes & Untreated eyes & P-value & Treated eyes & Untreated eyes & $P$-value \\
\hline ECD $\left(\right.$ cells $\left./ \mathrm{mm}^{2}\right)$ & $2,515.0 \pm 422.3$ & $2,495.5 \pm 435.9$ & 0.83 & $2,528.5 \pm 441.5$ & $2,524.1 \pm 436.8$ & 0.96 \\
AVG $\left(\mu \mathrm{m}^{2}\right)$ & $410.7 \pm 81.4$ & $415.8 \pm 92.7$ & 0.78 & $412.5 \pm 96.7$ & $413.8 \pm 102.8$ & 0.95 \\
SD $(\mu \mathrm{m})$ & $111.2 \pm 32.4$ & $114.2 \pm 35.9$ & 0.67 & $111.8 \pm 32.9$ & $110.3 \pm 30.4$ & 0.82 \\
CoV & $28.4 \pm 4.5$ & $29.0 \pm 5.4$ & 0.53 & $28.7 \pm 4.4$ & $28.3 \pm 4.5$ & 0.70 \\
MAX $\left(\mu \mathrm{m}^{2}\right)$ & $1,070.1 \pm 220.4$ & $1,115.5 \pm 261.7$ & 0.37 & $1,138.9 \pm 251.5$ & $1,132.2 \pm 249.4$ & 0.90 \\
MIN $\left(\mu \mathrm{m}^{2}\right)$ & $146.3 \pm 28.4$ & $153.1 \pm 34.9$ & 0.31 & $146.1 \pm 27.2$ & $146.5 \pm 18.4$ & 0.93 \\
Hex $(\%)$ & $67.5 \pm 4.9$ & $69.0 \pm 5.8$ & 0.18 & $67.6 \pm 5.3$ & $66.8 \pm 5.2$ & 0.48 \\
CCT $(\mu \mathrm{m})$ & $541.7 \pm 27.8$ & $546.2 \pm 33.3$ & 0.48 & $543.2 \pm 27.1$ & $546.0 \pm 28.2$ & 0.64 \\
IOP $(\mathrm{mmHg})$ & $13.3 \pm 3.2$ & $13.8 \pm 3.4$ & 0.52 & $12.5 \pm 2.7$ & $13.6 \pm 2.9$ & 0.049 \\
\hline
\end{tabular}

Note: Data are presented as mean \pm SD.

Abbreviations: Al, after injection; AVG, average cell size; CCT, central corneal thickness; CME, cystoid macular edema; CoV, coefficient of variation of cell size; DME, diabetic macular edema; ECD, endothelial cell density; Hex, hexagonal cells; MAX, maximum of cell size; MIN, minimum of cell size; RVO, retinal vein occlusion.

The measurements obtained at all time points were compared between eyes subjected to single and multiple intravitreal aflibercept injection, and the results are presented in Tables 6 and 7. Again, of all evaluated parameters, only MAX differed significantly at 3 months after the intravitreal injections.

\section{IOP}

The mean IOPs before injection and at 1, 3 and 6 months after the initial injection were $13.3 \pm 3.2,12.5 \pm 2.7,13.0 \pm 3.2$ and $12.8 \pm 2.9 \mathrm{mmHg}$, respectively (Table 1 ). The difference between time points was not statistically significant $(P=0.55)$.

A comparison of the mean IOPs of treated and untreated eyes measured before and 1,3 and 6 months after the initial injection yielded the following: $13.3 \pm 3.2$ vs $13.8 \pm 3.4$, $12.5 \pm 2.7$ vs $13.6 \pm 2.9,13.0 \pm 3.2$ vs $13.3 \pm 3.1$ and $12.8 \pm 2.9$ vs $13.6 \pm 3.3 \mathrm{mmHg}$, respectively (Tables 2 and 3). Only the difference at 1 month was statistically significant.

A comparison of the mean IOPs of patients with DME and CME due to RVO obtained before and 1, 3 and 6 months after the initial injection yielded the following: $14.2 \pm 3.1 \mathrm{vs}$ $12.8 \pm 3.2,13.3 \pm 2.8$ vs $12.0 \pm 2.4,12.6 \pm 3.0$ vs $13.3 \pm 3.1$ and $13.2 \pm 2.9$ vs $12.3 \pm 3.0 \mathrm{mmHg}$, respectively (Tables 4 and 5). These differences were not statistically significant at any time point.

Furthermore, a comparison of the mean IOPs measured before injection and 1, 3 and 6 months after the initial injection in eyes receiving single or multiple intravitreal doses of aflibercept yielded the following: $13.4 \pm 3.3$ vs $13.1 \pm 3.2$, $12.3 \pm 2.6$ vs $12.8 \pm 2.7,12.4 \pm 2.8$ vs $14.1 \pm 3.4$ and $12.3 \pm 2.6$ vs $13.3 \pm 3.4 \mathrm{mmHg}$, respectively (Tables 6 and 7). These differences were not statistically significant at any time point.

Table 3 Morphometric analysis of the corneal endothelium in the treated and untreated eyes at 3 and 6 months after the intravitreal injection of aflibercept in patients with DME and CME due to RVO

\begin{tabular}{l|l|l|l|l|l|l}
\hline & \multicolumn{3}{l}{3 months AI } & 6 months Al & \multicolumn{2}{l}{} \\
\cline { 2 - 7 } & Treated eyes & Untreated eyes & P-value & Treated eyes & Untreated eyes & P-value \\
\hline ECD $($ cells $/ \mathrm{mm})$ & $2,500.0 \pm 427.1$ & $2,487.0 \pm 422.3$ & 0.88 & $2,550.5 \pm 451.1$ & $2,492.4 \pm 447.4$ & 0.54 \\
AVG $\left(\mu \mathrm{m}^{2}\right)$ & $415.5 \pm 98.0$ & $418.7 \pm 109.2$ & 0.88 & $409.0 \pm 103.8$ & $419.8 \pm 115.2$ & 0.64 \\
SD $(\mu \mathrm{m})$ & $115.2 \pm 33.8$ & $115.1 \pm 35.5$ & 0.98 & $113.1 \pm 32.8$ & $115.4 \pm 46.2$ & 0.78 \\
CoV & $29.4 \pm 5.6$ & $29.2 \pm 6.7$ & 0.89 & $29.3 \pm 4.4$ & $28.9 \pm 5.7$ & 0.70 \\
MAX $(\mu \mathrm{m})$ & $1,180.6 \pm 283.5$ & $1,122.5 \pm 254.3$ & 0.30 & $1,041.5 \pm 238.7$ & $1,149.1 \pm 272.1$ & 0.047 \\
MIN $(\mu \mathrm{m})$ & $145.0 \pm 16.2$ & $147.6 \pm 25.4$ & 0.57 & $146.6 \pm 19.7$ & $145.0 \pm 24.7$ & 0.74 \\
Hex $(\%)$ & $66.9 \pm 6.4$ & $69.0 \pm 5.9$ & 0.12 & $66.5 \pm 6.0$ & $68.6 \pm 5.8$ & 0.11 \\
CCT $(\mu \mathrm{m})$ & $541.7 \pm 29.1$ & $544.7 \pm 30.4$ & 0.63 & $542.4 \pm 28.1$ & $544.9 \pm 28.3$ & 0.67 \\
IOP $(\mathrm{mmHg})$ & $13.0 \pm 3.2$ & $13.3 \pm 3.1$ & 0.65 & $12.8 \pm 2.9$ & $13.6 \pm 3.3$ & 0.22 \\
\hline
\end{tabular}

Note: Data are presented as mean \pm SD.

Abbreviations: Al, after injection; AVG, average cell size; CCT, central corneal thickness; CME, cystoid macular edema; CoV, coefficient of variation of cell size; DME, diabetic macular edema; ECD, endothelial cell density; Hex, hexagonal cells; MAX, maximum of cell size; MIN, minimum of cell size; RVO, retinal vein occlusion. 
Table 4 Morphometric analysis of the corneal endothelium in the treated eye before and I month after the intravitreal injection of aflibercept in patients with DME vs CME due to RVO

\begin{tabular}{|c|c|c|c|c|c|c|}
\hline & \multicolumn{3}{|c|}{ Before injection } & \multicolumn{3}{|l|}{ I month Al } \\
\hline & DME & CME due to RVO & $P$-value & DME & CME due to RVO & $P$-value \\
\hline $\mathrm{ECD}\left(\mathrm{cells} / \mathrm{mm}^{2}\right)$ & $2,503.1 \pm 4 \mid 9.2$ & $2,528.2 \pm 440.0$ & 0.85 & $2,542.3 \pm 379.2$ & $2,535.8 \pm 488.8$ & 0.96 \\
\hline $\operatorname{AVG}\left(\mu \mathrm{m}^{2}\right)$ & $4 \mid 2.0 \pm 80.4$ & $409.5 \pm 85.2$ & 0.92 & $405.8 \pm 69.3$ & $4|4.7 \pm| \mid 4.6$ & 0.75 \\
\hline $\mathrm{SD}(\mu \mathrm{m})$ & $113.5 \pm 33.9$ & $110.3 \pm 32.3$ & 0.75 & $113.0 \pm 27.4$ & $110.7 \pm 37.5$ & 0.81 \\
\hline $\mathrm{CoV}$ & $29.0 \pm 5.4$ & $28.2 \pm 3.6$ & 0.57 & $29.6 \pm 5.4$ & $28.0 \pm 3.4$ & 0.27 \\
\hline $\operatorname{MAX}\left(\mu \mathrm{m}^{2}\right)$ & $I, 063 . I \pm 249.5$ & I,08।.2 $2 \pm 203.7$ & 0.80 & I, $|7| .6 \pm 286.5$ & I,I $20.5 \pm 229.7$ & 0.53 \\
\hline $\operatorname{MIN}\left(\mu \mathrm{m}^{2}\right)$ & $|52.2 \pm 4| .7$ & $|42.8 \pm| \mid .8$ & 0.35 & $148.4 \pm 36.4$ & $144.0 \pm 19.2$ & 0.64 \\
\hline $\operatorname{Hex}(\%)$ & $67.6 \pm 5.6$ & $67.3 \pm 4.6$ & 0.86 & $66.5 \pm 6.4$ & $68.5 \pm 4.4$ & 0.25 \\
\hline ССТ $(\mu \mathrm{m})$ & $546.4 \pm 26.7$ & $538.2 \pm 29.1$ & 0.34 & $550.5 \pm 24.0$ & $539.3 \pm 28.1$ & 0.17 \\
\hline IOP $(\mathrm{mmHg})$ & $14.2 \pm 3.1$ & $12.8 \pm 3.2$ & 0.16 & $13.3 \pm 2.8$ & $12.0 \pm 2.4$ & 0.10 \\
\hline
\end{tabular}

Note: Data are presented as mean \pm SD.

Abbreviations: Al, after injection; AVG, average cell size; CCT, central corneal thickness; CME, cystoid macular edema; CoV, coefficient of variation of cell size; DME, diabetic macular edema; ECD, endothelial cell density; Hex, hexagonal cells; MAX, maximum of cell size; MIN, minimum of cell size; RVO, retinal vein occlusion.

\section{Discussion}

Experimental animal models have demonstrated that intravitreal injections yield adequate concentrations of ranibizumab, ${ }^{22}$ bevacizumab ${ }^{8}$ and aflibercept ${ }^{23}$ in the anterior chamber. However, the intracameral injection of ranibizumab and bevacizumab was shown to reduce corneal endothelial cell densities. ${ }^{24}$ Taken together, these data underscore the importance of determining the effects of intravitreal aflibercept injection on corneal endothelial cells. In the present study, these injections did not generally adversely affect the corneal endothelial cells, and no significant changes were observed in any parameter except the MAX cell size during the 6-month follow-up. Three inter-group comparisons revealed differences in IOP between treated and untreated eyes at 1 month after injection, in MAX between treated and untreated eyes at 6 months after injection and in MAX between eyes receiving single and multiple injections at
3 months after injection. No significant differences were observed between patients with DME and CME due to $\mathrm{RVO}$ at any time point. The corneal endothelium in diabetic patients is vulnerable compared to that of normal patients and susceptible to surgical stress. ${ }^{17,18}$ However, the current study findings suggest that an intravitreal injection of aflibercept might not represent a relevant surgical stress. As we mentioned previously, only MAX differed significantly at 3 months after the injection when eyes receiving single vs multiple intravitreal injections of aflibercept were compared. Therefore, only slight differences between the administration of single and multiple injections were observed.

\section{Limitations}

There are several limitations of our study, such as the small sample size, short follow-up period and low average number of injections (1.43 times/6 months).

Table 5 Morphometric analysis of the corneal endothelium in the treated eye at 3 and 6 months after the intravitreal injection of aflibercept in patients with DME vs CME due to RVO

\begin{tabular}{|c|c|c|c|c|c|c|}
\hline & \multicolumn{3}{|l|}{3 months Al } & \multicolumn{3}{|l|}{6 months Al } \\
\hline & DME & $\begin{array}{l}\text { CME due to } \\
\text { RVo }\end{array}$ & $P$-value & DME & $\begin{array}{l}\text { CME due to } \\
\text { RVo }\end{array}$ & $P$-value \\
\hline ECD (cells/mm) & $2,5 \mid 4.2 \pm 463.8$ & $2,487.0 \pm 422.3$ & 0.87 & $2,539.3 \pm 367.8$ & $2,542.0 \pm 510.9$ & 0.98 \\
\hline AVG $(\mu \mathrm{m})$ & $4 \mid 7.5 \pm 116.5$ & $418.7 \pm 109.2$ & 0.83 & $403.0 \pm 68.8$ & $416.2 \pm 125.3$ & 0.65 \\
\hline $\mathrm{SD}(\mu \mathrm{m})$ & $112.6 \pm 35.6$ & $115.1 \pm 35.5$ & 0.53 & $114.7 \pm 22.2$ & $1 \mid 3.1 \pm 39.3$ & 0.87 \\
\hline CoV & $28.4 \pm 2.8$ & $29.2 \pm 6.7$ & 0.22 & $30.5 \pm 5.7$ & $28.5 \pm 3.1$ & 0.19 \\
\hline $\operatorname{MAX}(\mu \mathrm{m})$ & $1,216.6 \pm 272.9$ & I, I $22.5 \pm 254.3$ & 0.43 & $\mathrm{I}, 018.4 \pm 164.5$ & I,066.0 283.9 & 0.48 \\
\hline $\operatorname{MIN}(\mu \mathrm{m})$ & $|43.8 \pm| 3.4$ & $147.6 \pm 25.4$ & 0.81 & $|5| .6 \pm 25.2$ & $|43.5 \pm| 4.3$ & 0.22 \\
\hline $\operatorname{Hex}(\%)$ & $67.4 \pm 5.3$ & $69.0 \pm 5.9$ & 0.58 & $64.5 \pm 7.0$ & $67.7 \pm 4.8$ & 0.091 \\
\hline ССТ $(\mu \mathrm{m})$ & $538.3 \pm 30.4$ & $544.7 \pm 30.4$ & 0.26 & $549.7 \pm 26.1$ & $537.0 \pm 29.4$ & 0.14 \\
\hline IOP (mmHg) & $12.6 \pm 3.0$ & $13.3 \pm 3.1$ & 0.13 & $13.2 \pm 2.9$ & $12.3 \pm 3.0$ & 0.32 \\
\hline
\end{tabular}

Note: Data are presented as mean \pm SD.

Abbreviations: Al, after injection; AVG, average cell size; CCT, central corneal thickness; CME, cystoid macular edema; CoV, coefficient of variation of cell size; DME, diabetic macular edema; ECD, endothelial cell density; Hex, hexagonal cells; MAX, maximum of cell size; MIN, minimum of cell size; RVO, retinal vein occlusion. 
Table 6 Morphometric analysis of the corneal endothelium in the treated eye before and I month after a single or multiple intravitreal injections of aflibercept in patients with DME and CME due to RVO

\begin{tabular}{|c|c|c|c|c|c|c|}
\hline & \multicolumn{3}{|l|}{ Before injection } & \multicolumn{3}{|l|}{ I month Al } \\
\hline & Single injection & $\begin{array}{l}\text { Multiple } \\
\text { injections }\end{array}$ & $P$-value & Single injection & $\begin{array}{l}\text { Multiple } \\
\text { injections }\end{array}$ & $P$-value \\
\hline ECD (cells/mm²) & $2,513.9 \pm 434.9$ & $2,498.7 \pm 426.6$ & 0.91 & $2,498.6 \pm 463.9$ & $2,575.0 \pm 4 \mid 2.8$ & 0.57 \\
\hline $\operatorname{AVG}\left(\mu \mathrm{m}^{2}\right)$ & $411.7 \pm 84.9$ & $412.7 \pm 79.9$ & 0.97 & $419.3 \pm 111.0$ & $401.9 \pm 70.5$ & 0.52 \\
\hline $\mathrm{SD}(\mu \mathrm{m})$ & $113.4 \pm 35.8$ & $110.4 \pm 27.5$ & 0.75 & $113.8 \pm 38.5$ & $108.8 \pm 22.5$ & 0.58 \\
\hline CoV & $28.7 \pm 4.7$ & $28.4 \pm 4.1$ & 0.83 & $28.5 \pm 4.8$ & $28.8 \pm 3.6$ & 0.81 \\
\hline $\operatorname{MAX}\left(\mu \mathrm{m}^{2}\right)$ & $1,060.9 \pm 250.5$ & $1,121.2 \pm 199.3$ & 0.37 & I,II $3.0 \pm 266.5$ & I,I $79.2 \pm 227.5$ & 0.39 \\
\hline $\operatorname{MIN}\left(\mu \mathrm{m}^{2}\right)$ & $141.3 \pm 11.9$ & $156.0 \pm 4 \mid .8$ & 0.88 & $142.5 \pm|5|$. & $151.7 \pm 39.3$ & 0.35 \\
\hline $\operatorname{Hex}(\%)$ & $67.6 \pm 5.1$ & $67.7 \pm 5.2$ & 0.97 & $67.5 \pm 6.1$ & $67.8 \pm 3.8$ & 0.82 \\
\hline $\mathrm{CCT}(\mu \mathrm{m})$ & $540.8 \pm 26.5$ & $540.3 \pm 32.5$ & 0.96 & $544.3 \pm 22.9$ & $54 I .6 \pm 33.1$ & 0.77 \\
\hline IOP (mmHg) & $13.4 \pm 3.3$ & $13.1 \pm 3.2$ & 0.71 & $12.3 \pm 2.6$ & $12.8 \pm 2.7$ & 0.47 \\
\hline
\end{tabular}

Note: Data are presented as mean \pm SD.

Abbreviations: Al, after injection; AVG, average cell size; CCT, central corneal thickness; CME, cystoid macular edema; CoV, coefficient of variation of cell size; DME, diabetic macular edema; ECD, endothelial cell density; Hex, hexagonal cells; MAX, maximum of cell size; MIN, minimum of cell size; RVO, retinal vein occlusion.

In general, intravitreal aflibercept injections are required every 2 months after three initial monthly doses to treat wet age-related macular degeneration ${ }^{25}$ in Japan. Lass et al ${ }^{16}$ assessed the effect of intravitreal aflibercept injection on corneal endothelium every 8 weeks after 3 monthly doses up to 52 weeks; on specular microscopy, no apparent corneal endothelial toxicity was observed because of intravitreal aflibercept injection. Intravitreal aflibercept injections were performed every 4 or 8 weeks after five initial monthly doses for DME in VIVID and VISTA studies; 5 the results of these large clinical trials led to the recommendation of the injections every 4 weeks after five initial monthly doses for DME in Japan. In contrast, intravitreal aflibercept injection pro re nata after a single dose is recommended for CME due to RVO in Japan. Although we initially considered pro re nata administration after five initial monthly intravitreal aflibercept injections for patients with DME, many patients rejected the high number of initial injections because of financial issues. Accordingly, we adopted the protocol of pro re nata administration after single intravitreal injection in our study.

Other factors may also affect the observed outcomes of intravitreal aflibercept injections. For example, retinal photocoagulation with an indirect ophthalmoscopy contact lens reportedly decreased the number of corneal endothelial cells. ${ }^{26}$ Accordingly, we addressed the effects of retinal photocoagulation on the corneal endothelium as much as possible. We additionally evaluated the mean IOP over the 6-month follow-up period and observed very slight changes between treated and untreated eyes at 1 month. Chhablani et $\mathrm{al}^{27}$ reported that a single intravitreal aflibercept injection $(2 \mathrm{mg})$ did not affect IOP after 1 month. Furthermore,

Table 7 Morphometric analysis of the corneal endothelium in the treated eye after 3 and 6 months single or multiple intravitreal aflibercept injections in patients with DME and CME due to RVO

\begin{tabular}{|c|c|c|c|c|c|c|}
\hline & \multicolumn{3}{|l|}{3 months Al } & \multicolumn{3}{|l|}{6 months Al } \\
\hline & Single injection & $\begin{array}{l}\text { Multiple } \\
\text { injections }\end{array}$ & $P$-value & Single injection & $\begin{array}{l}\text { Multiple } \\
\text { injections }\end{array}$ & $P$-value \\
\hline ECD (cells/mm) & $2,478.6 \pm 45 \mid .5$ & $2,533.6 \pm 396.5$ & 0.67 & $2,499.8 \pm 487.1$ & $2,589.1 \pm 387.0$ & 0.49 \\
\hline AVG $(\mu \mathrm{m})$ & $422.5 \pm I \mid 3.1$ & $404.6 \pm 69.8$ & 0.51 & $421.4 \pm 120.8$ & $395.7 \pm 68.3$ & 0.36 \\
\hline $\mathrm{SD}(\mu \mathrm{m})$ & $120.4 \pm 39.4$ & $107.2 \pm 21.1$ & 0.15 & $118.9 \pm 37.8$ & $105.9 \pm 20.4$ & 0.14 \\
\hline CoV & $30.2 \pm 6.5$ & $28.1 \pm 3.6$ & 0.17 & $30.0 \pm 4.5$ & $28.3 \pm 4.1$ & 0.21 \\
\hline $\operatorname{MAX}(\mu \mathrm{m})$ & I, I08.3 \pm 263.9 & I,293.2 283.0 & 0.029 & $1,024.8 \pm 184.9$ & I,07|.7 $7 \pm 306.3$ & 0.56 \\
\hline $\mathrm{MIN}(\mu \mathrm{m})$ & $146.0 \pm 19.3$ & $143.4 \pm 9.9$ & 0.55 & $144.8 \pm \mid 7.7$ & $149.7 \pm 22.5$ & 0.44 \\
\hline $\operatorname{Hex}(\%)$ & $66.5 \pm 7.1$ & $67.7 \pm 5.1$ & 0.51 & $65.9 \pm 5.9$ & $67.6 \pm 6.4$ & 0.38 \\
\hline CCT $(\mu \mathrm{m})$ & $541.6 \pm 25.9$ & $541.8 \pm 34.2$ & 0.98 & $540.0 \pm 26.5$ & $543.8 \pm 32.6$ & 0.68 \\
\hline IOP $(\mathrm{mmHg})$ & $12.4 \pm 2.8$ & $14.1 \pm 3.4$ & 0.086 & $12.3 \pm 2.6$ & $13.3 \pm 3.4$ & 0.31 \\
\hline
\end{tabular}

Note: Data are presented as mean \pm SD.

Abbreviations: Al, after injection; AVG, average cell size; CCT, central corneal thickness; CME, cystoid macular edema; CoV, coefficient of variation of cell size; DME, diabetic macular edema; ECD, endothelial cell density; Hex, hexagonal cells; MAX, maximum of cell size; MIN, minimum of cell size; RVO, retinal vein occlusion. 
several case series have reported sterile inflammation after intravitreal aflibercept injections. ${ }^{28-31}$ Although no cases of sterile inflammation were observed in the current study, the previous reports raised concerns about the potential effects of sterile inflammation on the corneal endothelium.

We further note that previous results from experimental animal models were not completely reliable because of the differences between animal and human tissues. Furthermore, although previous studies on intravitreal bevacizumab, ${ }^{32}$ ranibizumab ${ }^{33,34}$ and aflibercept ${ }^{16}$ injections did not report effects on the human corneal endothelium, the safety of use of aflibercept on human tissues is a very important issue facing clinical practice. However, our findings very slightly differed from previous reports describing the effects of anti-VEGF antibodies. ${ }^{16,32-34}$ As intravitreal anti-VEGF antibody injections will be used for the treatment of many retinal diseases in future, considerable attention must be paid to not only the effectiveness but also the potential adverse effects.

\section{Conclusion}

The results of this clinical study indicate that an intravitreal injection of aflibercept ( $2 \mathrm{mg}$ ) might induce corneal endothelial damage or very slight changes in corneal endothelial cells within 6 months of the first injection. Corneal endothelial damage can lead to partial abnormal corneal hydration and, consequently, corneal edema. Our findings warrant further studies regarding the potential side effects of intravitreal aflibercept injection on the human corneal endothelium.

\section{Disclosure}

The authors report no conflicts of interest in this work.

\section{References}

1. Oellers P, Grewal DS, Fekrat S. Role of aflibercept for macular edema following branch retinal vein occlusion: comparison of clinical trials. Clin Ophthalmol. 2016;10:411-418.

2. Ogura Y, Roider J, Korobelnik JF, et al. Intravitreal aflibercept for macular edema secondary to central retinal vein occlusion: 18-month results of the phase 3 Galileo study. Am J Ophthalmol. 2014;158(5): 1032-1038.

3. Boyer D, Heier J, Brown DM, et al. Vascular endothelial growth factor Trap-Eye for macular edema secondary to central retinal vein occlusion: six-month results of the phase 3 COPERNICUS study. Ophthalmology. 2012;119(5):1024-1032.

4. Heier JS, Clark WL, Boyer DS, et al. Intravitreal aflibercept injection for macular edema due to central retinal vein occlusion: two-year results from the COPERNICUS study. Ophthalmology. 2014;121(7): 1414-1420.

5. Brown DM, Schmidt-Erfurth U, Do DV, et al. Intravitreal aflibercept for diabetic macular edema: 100 -week results from the VISTA and vivid studies. Ophthalmology. 2015;122(10):2044-2052.

6. Korobelnik JF, Do DV, Schmidt-Erfurth U, et al. Intravitreal aflibercept for diabetic macular edema. Ophthalmology. 2014;121(11):2247-2254.
7. Campochiaro PA, Clark WL, Boyer DS, et al. Intravitreal aflibercept for macular edema following branch retinal vein occlusion: the 24-week results of the VIBRANT study. Ophthalmology. 2015;122(3):538-544.

8. Bakri SJ, Snyder MR, Reid JM, Pulido JS, Singh RJ. Pharmacokinetics of intravitreal bevacizumab (Avastin). Ophthalmology. 2007;114(5): 855-859.

9. Gan L, Fagerholm P, Palmblad J. Vascular endothelial growth factor (VEGF) and its receptor VEGFR-2 in the regulation of corneal neovascularization and wound healing. Acta Ophthalmol Scand. 2004;82(5): 557-563.

10. Philipp W, Speicher L, Humpel C. Expression of vascular endothelial growth factor and its receptors in inflamed and vascularized human corneas. Invest Ophthalmol Vis Sci. 2000;41(9):2514-2522.

11. Ambati BK, Nozaki M, Singh N, et al. Corneal avascularity is due to soluble VEGF receptor-1. Nature. 2006;443(7114):993-997.

12. Bayar SA, Altinors DD, Kucukerdonmez C, Akova YA. Severe corneal changes following intravitreal injection of bevacizumab. Ocul Immunol Inflamm. 2010;18(4):268-274.

13. Klettner A, Tahmaz N, Dithmer M, Richert E, Roider J. Effects of aflibercept on primary RPE cells: toxicity, wound healing, uptake and phagocytosis. Br J Ophthalmol. 2014;98(10):1448-1452.

14. Acar U, Erginturk Acar D, Alpaslan Pinarli F, et al. Effects of commonly used intravitreal anti-vascular endothelial growth factor drugs on mesenchymal stem cells derived from the limbus and ciliary body. Clin Exp Ophthalmol. 2016;44(7):587-596.

15. Stewart MW, Rosenfeld PJ. Predicted biological activity of intravitreal VEGF trap. Br J Ophthalmol. 2008;92(5):667-668.

16. Lass JH, Benetz BA, Menegay HJ, et al. Effects of repeated intravitreal aflibercept injection on the corneal endothelium in patients with agerelated macular degeneration: outcomes from the RE-VIEW study. Cornea. 2018;37(5):596-601.

17. Morikubo S, Takamura Y, Kubo E, Tsuzuki S, Akagi Y. Corneal changes after small-incision cataract surgery in patients with diabetes mellitus. Arch Ophthalmol. 2004;122(7):966-969.

18. Tsaousis KT, Panagiotou DZ, Kostopoulou E, Vlatsios V, Stampouli D. Corneal oedema after phacoemulsification in the early postoperative period: a qualitative comparative case-control study between diabetics and non-diabetics. Ann Med Surg. 2016;5:67-71.

19. Schultz RO, Matsuda M, Yee RW, Edelhauser HF, Schultz KJ. Corneal endothelial changes in type I and type II diabetes mellitus. Am J Ophthalmol. 1984;98(4):401-410.

20. Geroski DH, Edelhauser HF. Morphometric analysis of the corneal endothelium specular microscopy vs. alizarin red staining. Invest Ophthalmol Vis Sci. 1989;30(2):254-259.

21. Ohara K, Tsuru T, Inoda S. Morphometric parameters of the corneal endothelial cells. J Jpn Ophthalmol Soc. 1987;91(11):1073-1078.

22. Bakri SJ, Snyder MR, Reid JM, et al. Pharmacokinetics of intravitreal ranibizumab (Lucentis). Ophthalmology. 2007;114(12):2179-2182.

23. Niwa Y, Kakinoki M, Sawada T, Wang X, Ohji M, Ranibizumab OM. Ranibizumab and aflibercept: intraocular pharmacokinetics and their effects on aqueous VEGF level in vitrectomized and nonvitrectomized macaque eyes. Invest Ophthalmol Vis Sci. 2015;56(11):6501-6505.

24. Ari S, Nergiz Y, Aksit I, Sahin A, Cingu K, Caca I. Evaluation of intracameral injection of ranibizumab and bevacizumab on the corneal endothelium by scanning electron microscopy. J Ocul Pharmacol Ther. 2015;31(2):100-105.

25. Heier JS, Brown DM, Chong V, et al. Intravitreal aflibercept (VEGF trap-eye) in wet age-related macular degeneration. Ophthalmology. 2012;119(12):2537-2548.

26. Murata H, Kato S, Fukushima H, Tsutsumi A, Numaga J, Amano S. Corneal endothelial cell density reduction: a complication of retinal photocoagulation with an indirect ophthalmoscopy contact lens. Acta Ophthalmol Scand. 2007;85(4):407-408.

27. Chhablani J, Dedhia CJ, Peguda HK, Stewart M. Short-term safety of $2 \mathrm{mg}$ intravitreal ziv-aflibercept. Retina. 2017;37(10):1859-1865.

28. Hahn P, Kim JE, Stinnett S, et al. Aflibercept-related sterile inflammation. Ophthalmology. 2013;120(5):1100-1101. 
29. Fine HF, Roth DB, Shah SP, Haque T, Wheatley HM. Frequency and characteristics of intraocular inflammation after aflibercept injection. Retina. 2015;35(4):681-686.

30. Goldberg RA, Shah CP, Wiegand TW, Heier JS. Noninfectious inflammation after intravitreal injection of aflibercept: clinical characteristics and visual outcomes. Am J Ophthalmol. 2014;158(4):733-737.

31. Kim JY, You YS, Kwon OW, Kim SH. Sterile inflammation after intravitreal injection of aflibercept in a Korean population. Korean $J$ Ophthalmol. 2015;29(5):325-330.

32. Chiang CC, Chen WL, Lin JM, Tsai YY. Effect of bevacizumab on human corneal endothelial cells: a six-month follow-up study. Am J Ophthalmol. 2008;146(5):688-691.
33. Pérez-Rico C, Benítez-Herreros J, Castro-Rebollo M, et al. Effect of intravitreal ranibizumab on corneal endothelium in age-related macular degeneration. Cornea. 2010;29(8):849-852.

34. Pérez-Rico C, Benítez-Herreros J, Castro-Rebollo M, et al. Endothelial cells analysis after intravitreal ranibizumab (Lucentis) in age-related macular degeneration treatment: a pilot study. Br J Ophthalmol. 2010; 94(2):267-268.

\section{Publish your work in this journal}

Clinical Ophthalmology is an international, peer-reviewed journal covering all subspecialties within ophthalmology. Key topics include: Optometry; Visual science; Pharmacology and drug therapy in eye diseases; Basic Sciences; Primary and Secondary eye care; Patien Safety and Quality of Care Improvements. This journal is indexed on

Submit your manuscript here: http://www.dovepress.com/clinical-ophthalmology-journal

\section{Dovepress}

PubMed Central and CAS, and is the official journal of The Society of Clinical Ophthalmology (SCO). The manuscript management system is completely online and includes a very quick and fair peer-review system, which is all easy to use. Visit http://www.dovepress.com/ testimonials.php to read real quotes from published authors. 